\title{
Influence of silica content in sulfonated polysulfone/ phosphotungstic acid hybrid membranes on properties for fuel cell application
}

\author{
Jian Zhang, Guoping Fei, Yile Liang, Youwei Zhang, Jiongxin Zhao*
}

*State Key Lab for Modification of Chemical Fiber and Polymer Materials, College of Material Science and Engineering, Donghua University, 2999 North Renmin Road, Shanghai 201620, P.R China; tel: 0086-021-67792852; fax: 0086-021-67792889; email: zjxin@dhu.edu.cn.

(Received: 27 February, 2009; published:29 September, 2010)

\begin{abstract}
The sulfonated polysulfone (SPSU)/phosphotungstic acid (PWA)/silica $\left(\mathrm{SiO}_{2}\right)$ hybrid membranes were researched for proton exchange membranes. The influence of silica content on the properties of composite membranes was studied in detail. The study displays that inorganic silica particles have a great influence on membrane properties, such as membrane durability, PWA extraction, proton and methanol transport behavior, thermal stability and water uptake. Interestingly, the hybrid membrane with 2 wt.\% silica content showed the best results: low PWA extraction, long membrane life time under oxidative condition, high proton conductivity, and low methanol permeability. However, excessive silica content caused a large aggregation of $\mathrm{SiO}_{2}$ particles, leading to the deterioration of membrane properties.
\end{abstract}

\section{Introduction}

Direct methanol fuel cells (DMFC) have attracted considerable attention for potential applications and advantages in view of their low weight, easy manipulation, high efficiency and low poison emission [1-4]. However, the current industry standard perfluorosulfonic polymers such as Nafion are limited by (a) high cost (b) high methanol permeability, and (c) loss of membrane performance at elevated temperatures. To overcome these drawbacks, in the past years, two classes of materials were investigated. One is polymeric material, including polysulfones [5-8], polyimides [9, 10], polybenzimidazoles [11-13] and poly(ether ether ketone) $[14,15]$ with diverse mechanical and electrical properties, higher efficiency and low cost. The other is organic-inorganic composite material with special interactions between organic and inorganic parts, which offers exceptional opportunities to create materials with unique properties. Among them the incorporation of highly conductive $\left(0.02-0.1 \mathrm{~s} \cdot \mathrm{cm}^{-1}\right.$ at room temperature) heteropolyacid such as phosphotungstic acid (PWA) and silicotungstic acid (SiWA) has shown encouraging results [16-19]. However, PWA or SiWA itself is water soluble, and is easily extracted from the composite membranes in the presence of hot water, which would result in a decrease in proton conductivity and other desirable performance. To manage this drawback, one can immobilize PWA inside a silica matrix. 
Therefore, in this paper, a kind of organic/inorganic composite membranes consisting of SPSU, PWA and $\mathrm{SiO}_{2}$ have been researched for proton exchange membranes. The main goal of this study is to systematically investigate the influence of silica content on the nanostructures and properties of the SPSU/PWA/SiO ${ }_{2}$ nanocomposite membranes and discuss the optimization of $\mathrm{SiO}_{2}$ content in the composite membranes with superior properties.

\section{Results and discussion}

\section{Thermal stability}

The TGA curves of SPSU/PWA/SiO 2 composite membranes measured under flowing nitrogen are shown in Fig.1. Thermal stability of the composites is observed at around $250-300{ }^{\circ} \mathrm{C}$ where the first weight losses occur; the second weight loss are observed around $400^{\circ} \mathrm{C}$. The former is assigned to sulfonic acid groups' elimination, and the latter is identified as SPSU backbone degradation. In addition, the weight remaining after the polymer decomposition depends on the content of the inorganic component. That is, the weight residues of the composite membranes with 0 wt. $\%, 4.8$ wt. $\%, 16.7$ wt. $\%$ and 23 wt. $\%$ silica at $\mathrm{T}=700{ }^{\circ} \mathrm{C}$ is $27.2 \%, 32.2 \%, 39.4 \%$, and $50 \%$, respectively. The result suggests that the introduction of silica into the SPSU chains enhances the thermal stability of the given hybrid materials. The increase in the thermal stability may have resulted from the high thermal stability of silica and the crosslink point of the silica particles [23].

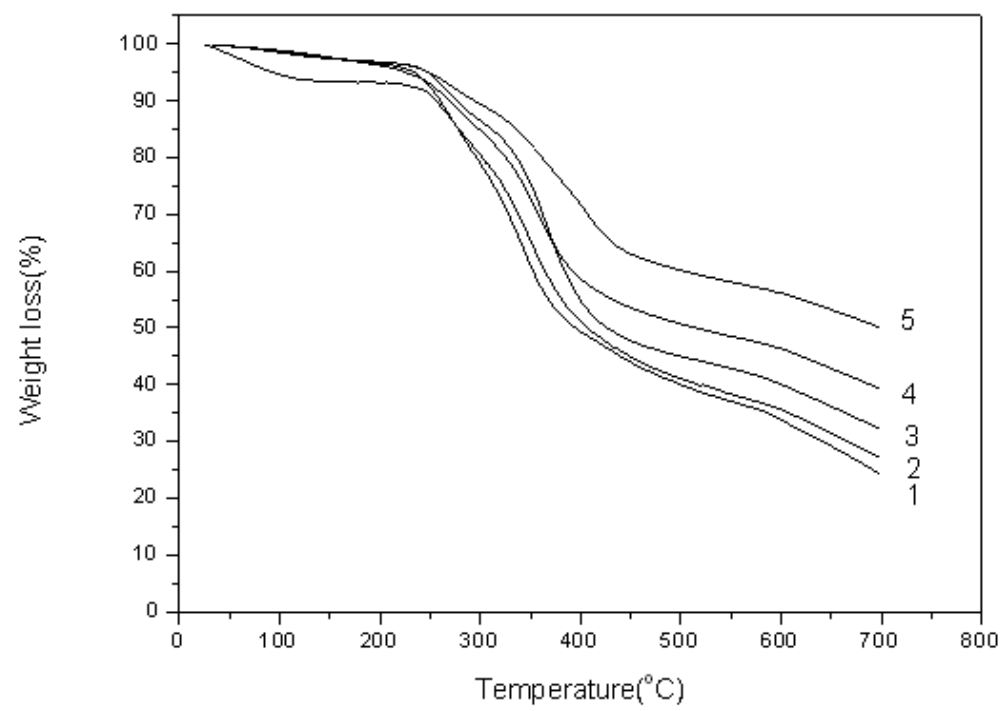

Fig. 1. TGA curves of SPSU/PWA/SiO 2 composite membranes.1: SPSU; 2: SPSU/PWA; 3: SPSU/PWA/SiO $2-4.8 \%$; 4: SPSU/PWA/SiO $2-16.7 \%$; 5: SPSU/PWA/ $\mathrm{SiO}_{2}-23 \%$

\section{Morphology studies}

Fig. 2. displays the electron micrographs of SPSU/PWA/SiO ${ }_{2}$ composite membranes with 1 wt. \%, 2wt.\% and $4.8 w t . \%$ of silica content. From Fig. 2(a),(b), it can be seen that the $\mathrm{SiO}_{2}$ and PWA particles are uniformly and well distributed over the membrane and do not form any agglomerations. The size of $\mathrm{SiO}_{2}$ and PWA particles is observed to be around $30 \mathrm{~nm}$. The silica particles in the composite membrane 
containing 4.8 wt.\% silica content show less uniformity in their distribution (Fig.2(c)). We can observe that the $\mathrm{SiO}_{2}$ filler dispersion is not homogeneous, but aggregates of some micron are formed, which will become larger and more continuous by increasing the silica content.

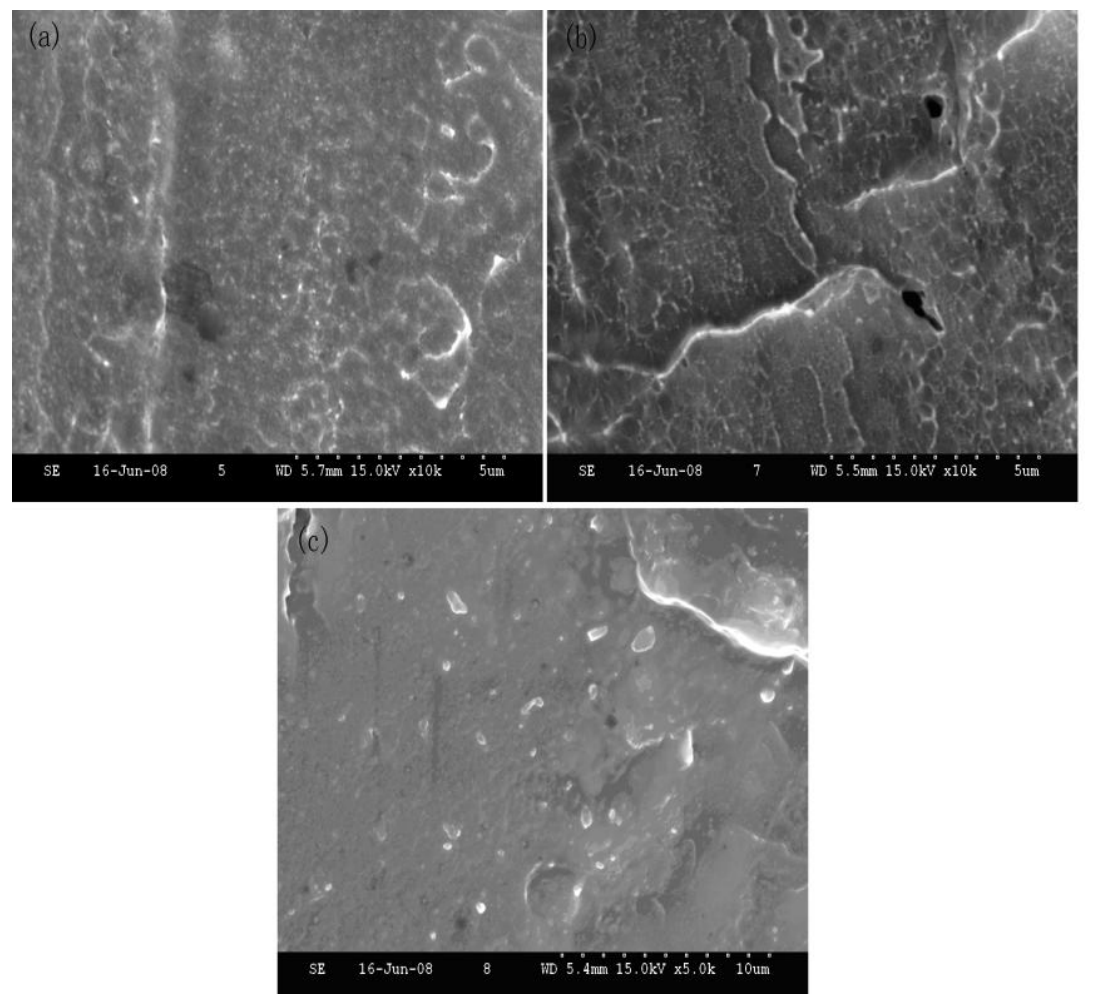

Fig. 2. SEM of composite membranes: (a) $1 \%$ silica; (b) $2 \%$ silica; (c) $4.8 \%$ silica.

\section{Water uptake}

The room temperature water uptake of SPSU/PWA/SiO ${ }_{2}$ composite membranes as a function of silica content is shown in Fig. 3.

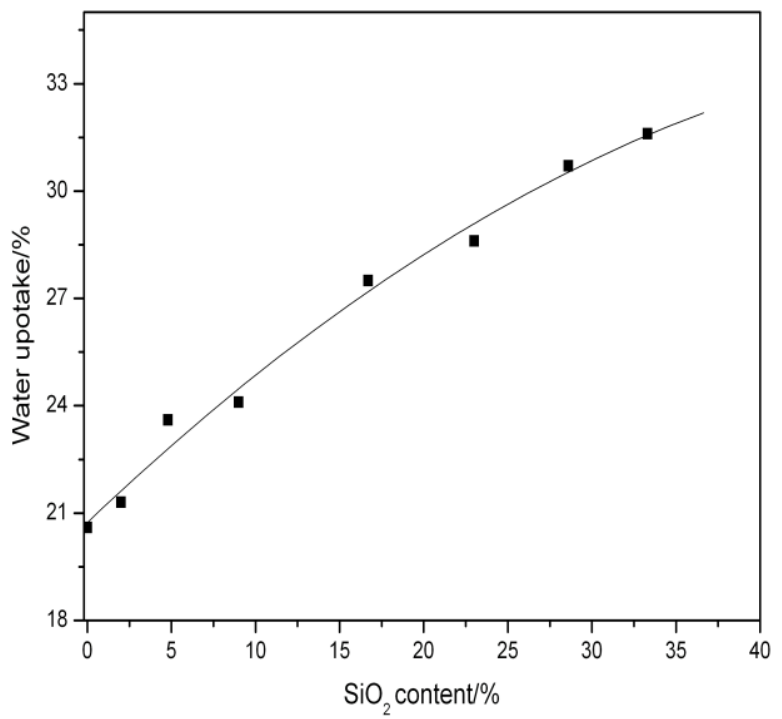

Fig. 3. Influence of silica content on the water uptake of composite membranes. 
As expected, the water uptake of the composite membrane increases as the silica particles content increase. For example, the water uptake of the film containing 2 wt.\% silica is $21.3 \%$, while the film loaded with 33.3 wt.\% silica showed a water uptake of $31.6 \%$. The introduction of silica enhances the membrane hydrophilicity due to the presence of numerous $\equiv \mathrm{SiOH}$ groups in the composites, which can form strong bonding with $\mathrm{H}_{2} \mathrm{O}$ molecules.

\section{PWA extraction}

The extraction of PWA is detected by UV-Vis recording spectrophotometer as mentioned after treatment in water and given in Table1. Differing from the general expectation that an increasing quantity of silica leads to a consecutive decrease of PWA extraction from the SPSU/PWA $/ \mathrm{SiO}_{2}$ composite membranes, a peculiar PWA extraction behavior is observed at $\mathrm{SiO}_{2}$ content above 2 wt.\%. When $\mathrm{SiO}_{2}$ content is below 2 wt.\%, PWA is stabilized within the silica skeleton, and the PWA extraction leaked out from the composites is negligible. However, it weakens the PWA stability of the corresponding composite membranes when $\mathrm{SiO}_{2}$ content above 2 wt.\%. This phenomenon can be well interpreted by morphology of composite membranes with different $\mathrm{SiO}_{2}$ content. The more well-dispersed $\mathrm{SiO}_{2}$ nanoparticles, the more PWA molecules were fixup tightly. However, $\mathrm{SiO}_{2}$ nanoparticles begin to aggregate over 2 wt.\%, that is why the stabilization of PWA within the silica skeleton is weakened.

Tab. 1. PWA extraction from composite membranes in water.

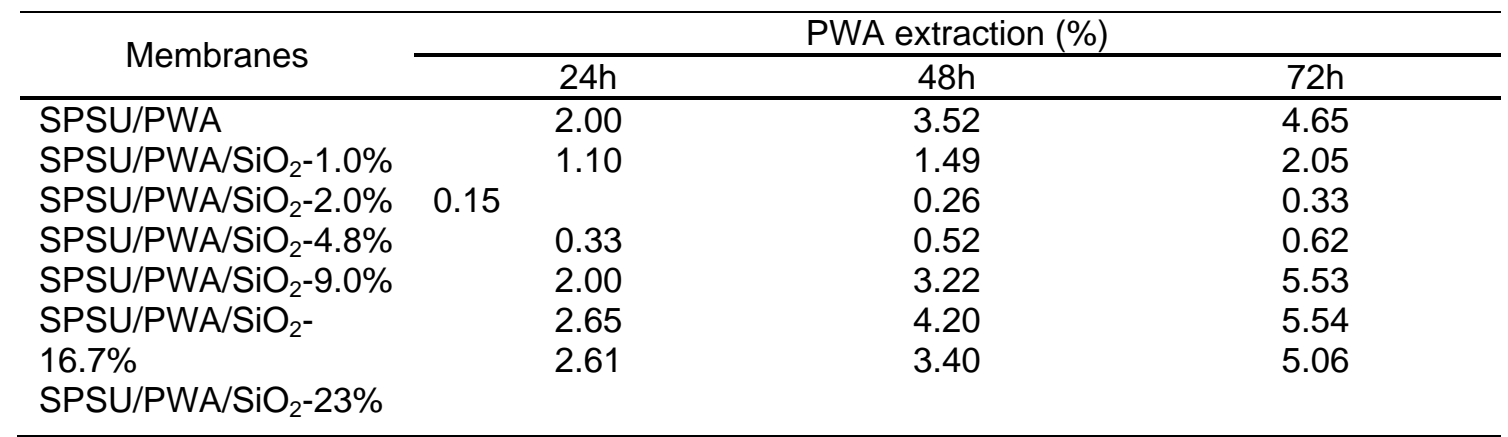

\section{Chemical stability and mechanical properties}

Table 2 gives examples for improvement of the oxidative stability of SPSU/PWA composite membranes via the incorporation of $\mathrm{SiO}_{2}$ particles. Hydrophilic silica particles seem to be effective in enhancing the tolerance of a radical attack dependent of $\mathrm{SiO}_{2}$ particles dispersion. This trend could be clearly observed in Table 2. Furthermore, the highest tolerance to free radical attack is observed in the composite membrane with 2 wt.\% silica content. The addition of silica above 2 wt.\% induces irregular aggregation of silica particles within the SPSU matrix, which is consistent with its nanostructure in SEM picture (Fig.3c), and weakens the chemical stability of the corresponding composite membranes.

The mechanical properties in Table 2 list physical parameters important in investigating optimal $\mathrm{SiO}_{2}$ content. The $\mathrm{SiO}_{2}$ particles act as reinforcing agents improving the tensile strength of $\mathrm{SPSU} / \mathrm{PWA} / \mathrm{SiO}_{2}$ composite membranes, but decreasing the elongation at break. However, adding excessive $\mathrm{SiO}_{2}$ content weakens both its tensile strength and elongation. In particular, the worsening of mechanical properties is visible at $\mathrm{SiO}_{2}$ content over $4.8 \mathrm{wt} . \%$. 
Tab. 2. Oxidative stabilities and mechanical properties of composite membranes.

\begin{tabular}{|c|c|c|c|}
\hline Membranes & Dissolving time(min) & Tensile strength(Mpa) & Elongation(\%) \\
\hline SPSU/PWA & 420 & 49.2 & 10.9 \\
\hline SPSU/PWA/SiO $2-1.0 \%$ & 900 & 66.7 & 10.6 \\
\hline SPSU/PWA $/ \mathrm{SiO}_{2}-2.0 \%$ & 1410 & 66.9 & 8.3 \\
\hline SPSU/PWA $/ \mathrm{SiO}_{2}-4.8 \%$ & 1200 & 49.6 & 6.5 \\
\hline SPSU/PWA/SiO $2-9.0 \%$ & 1020 & 43.7 & 3.7 \\
\hline $\mathrm{SPSU} / \mathrm{PWA} / \mathrm{SiO}_{2}-16.7 \%$ & 600 & 29.5 & 2.6 \\
\hline SPSU/PWA/SiO $2-23 \%$ & 510 & 16.4 & 1.8 \\
\hline
\end{tabular}

\section{Proton conductivity}

Fig. 4 shows the proton conductivities of SPSU/PWA/SiO ${ }_{2}$ composite membranes with various content of $\mathrm{SiO}_{2}$ content at $30^{\circ} \mathrm{C}$ and $80^{\circ} \mathrm{C}$. In region I, it is apparent that the addition of silica below $2 \mathrm{wt} . \%$ seems to be somewhat effective in increasing the proton conductivity. This phenomenon is consistent with those reported by others $[24,25]$. However, in region II, an excess of the silica phase could result in a counter effect. It is considered that an excess of the silica phase inhibits proton conduction in the membrane $[26,27]$. With the silica content 2 wt.\%, the proton conductivity of the composites at $80{ }^{\circ} \mathrm{C}$ is $0.134 \mathrm{~s}^{-\mathrm{cm}^{-1}}$, which is comparable to the result of Nafion 117 at the same test conditions.

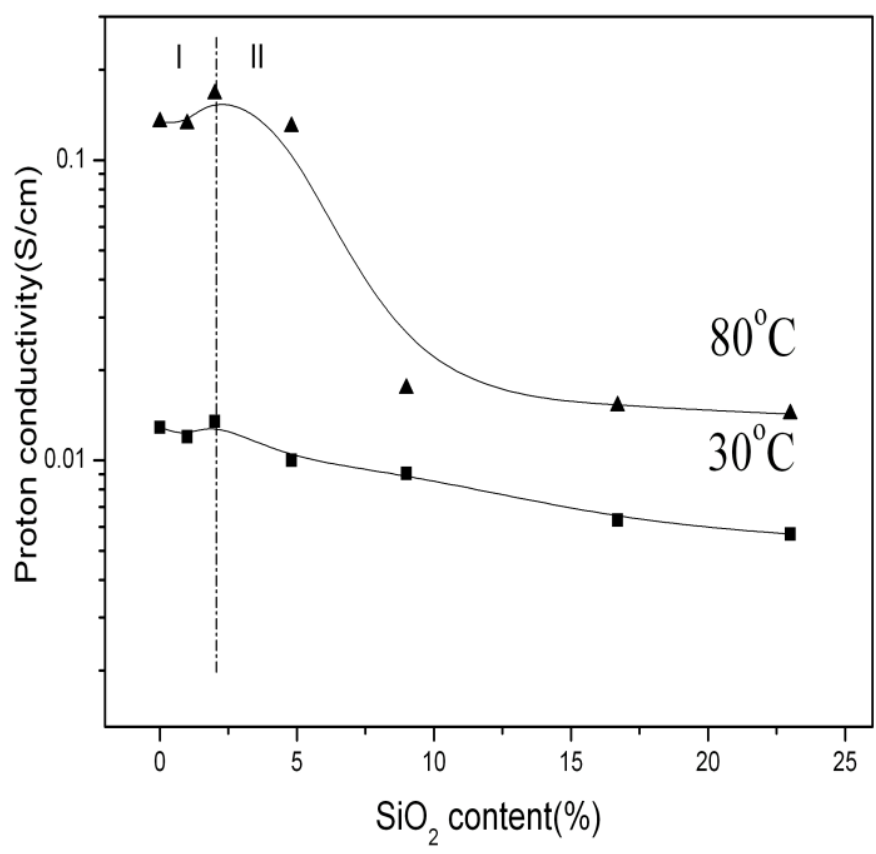

Fig. 4. Effect of $\mathrm{SiO}_{2}$ content on proton conductivity in the composite membranes.

\section{Methanol permeability}

Fig.5(a) shows the methanol permeability of the SPSU/PWA/SiO ${ }_{2}$ composite membranes. In region I, for these membranes, the values decrease with the existence of $\mathrm{SiO}_{2}$. In particular, the lowest methanol permeability is also observed in the composite with $2 \mathrm{wt} . \% \mathrm{SiO}_{2}$ content and its methanol permeability, at $30{ }^{\circ} \mathrm{C}$ and $80^{\circ} \mathrm{C}$, is $3.46 \times 10^{-7} \mathrm{~cm}^{2} \cdot \mathrm{s}^{-1}$ and $7.5 \times 10^{-7} \mathrm{~cm}^{2} \cdot \mathrm{s}^{-1}$, respectively, which is about an order of magnitude lower than Nafion 117. The well-dispersed $\mathrm{SiO}_{2}$ nanoparticles play an 
important role in decreasing permeability via reduction of free volume within the SPSU matrix. However, in region II, the excess addition of silica content results in aggregation of silica particles within the SPSU matrix, also resulting in a counter effect. An agglomeration of the $\mathrm{SiO}_{2}$ nanoparticles physically hinders interaction among SPSU chains, and their average interchain distance increases, which results in low methanol barrier properties. These analyses imply that the composites with higher content of $\mathrm{SiO}_{2}$ do not always show better cell performance.
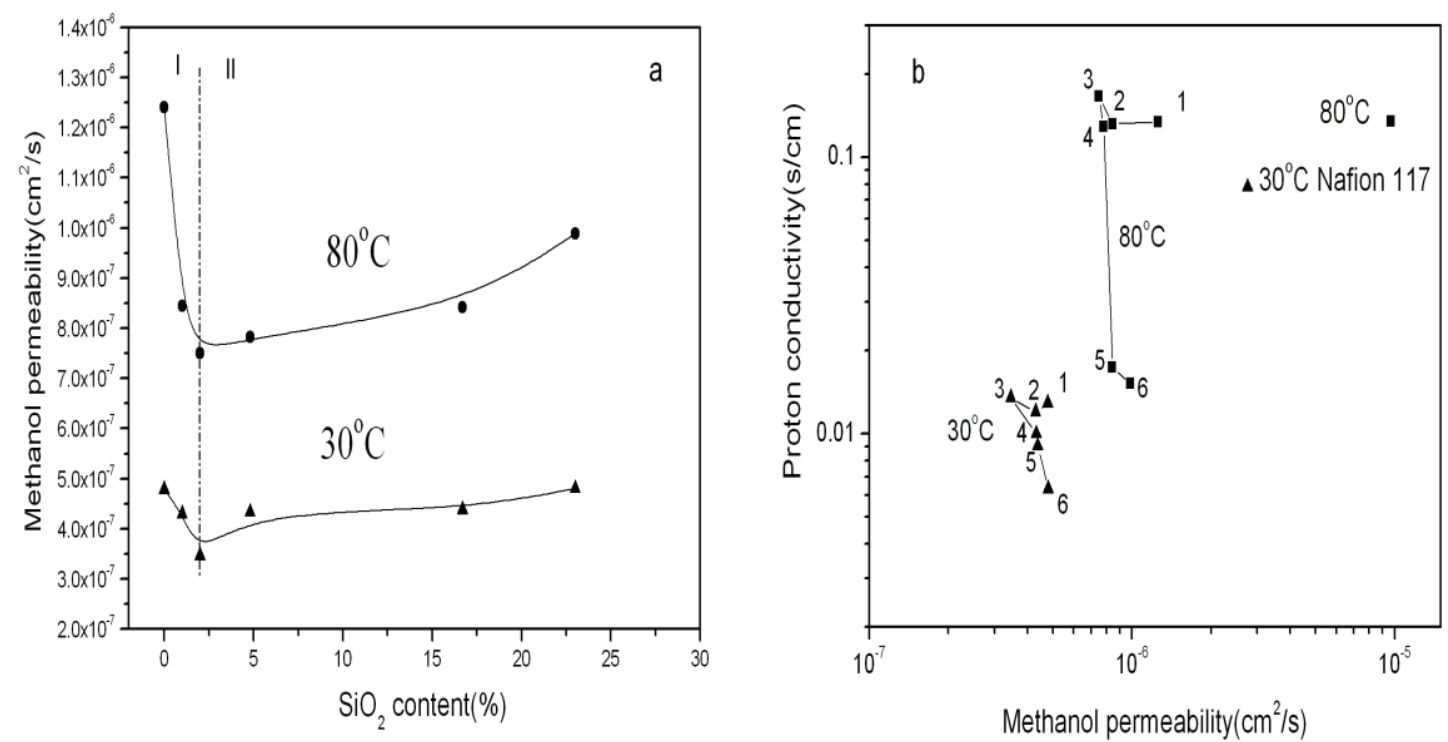

Fig. 5. (a) Effect of $\mathrm{SiO}_{2}$ content on methanol permeability in the composite membranes; Fig. 5(b) Proton conductivities versus methanol permeabilities (1: 0\% silica content; 2: $1 \%$ silica content; 3 : $2 \%$ silica content; $4: 4.8 \%$ silica content; $5: 9 \%$ silica content; $6: 16.7 \%$ silica content)

Fig. 5(b) shows the proton conductivities and methanol permeabilities of hybrid membranes and Nafion 117 at $30{ }^{\circ} \mathrm{C}$ and $80^{\circ} \mathrm{C}$. Generally, the proton conductivity has a strong trade-off relationship with the methanol permeability [28]. A target membrane would be located in the upper left-hand corner. From the picture, we can see that the optimum silica content in the composite membranes is about 2 wt.\%. The membranes with above 2 wt.\% silica content (from point 4 to 6 ) show a very vertical trend. That means the methanol permeability of membranes with above 2 wt.\% silica remains unchanged, while the proton conductivity decreases abruptly.

\section{Conclusions}

SPSU/PWA/SiO ${ }_{2}$ composite membranes with different $\mathrm{SiO}_{2}$ weight content were researched for DMFC. The study showed that $\mathrm{SiO}_{2}$ content plays an important role in microstructures and membrane properties. The results showed that well-dispersed $\mathrm{SiO}_{2}$ nanoparticles is effective in lowering PWA extraction and methanol permeability and enhancing proton conductivity in nanocomposite membranes. PWA stability within the silica skeleton increased up to $2 \mathrm{wt} . \% \mathrm{SiO}_{2}$, but rapidly decreased above about 5 wt.\%. The trends in methanol barrier property, chemical stability and mechanical properties were very similar to those of the PWA stability within the SPSU matrix. The composite membrane with 2 wt.\% silica content showed the best 
results, whereas excessive silica content caused a large aggregation of $\mathrm{SiO}_{2}$ particles, leading to the deterioration of membrane properties. In the present study, the optimum silica content in the nanocomposite membranes is about $2 \mathrm{wt} . \%$.

\section{Experimental}

\section{Materials}

Sulfonated polysulfone was prepared via a direct sulfonation method as described in our previous work [20]. The chemical structure and the preparation of SPSU are shown in Scheme 1. PWA was obtained from chemical plants in Shanghai, China and was used as received. Silica gel was obtained from Qingdao Haiyang Chemical Group Company.

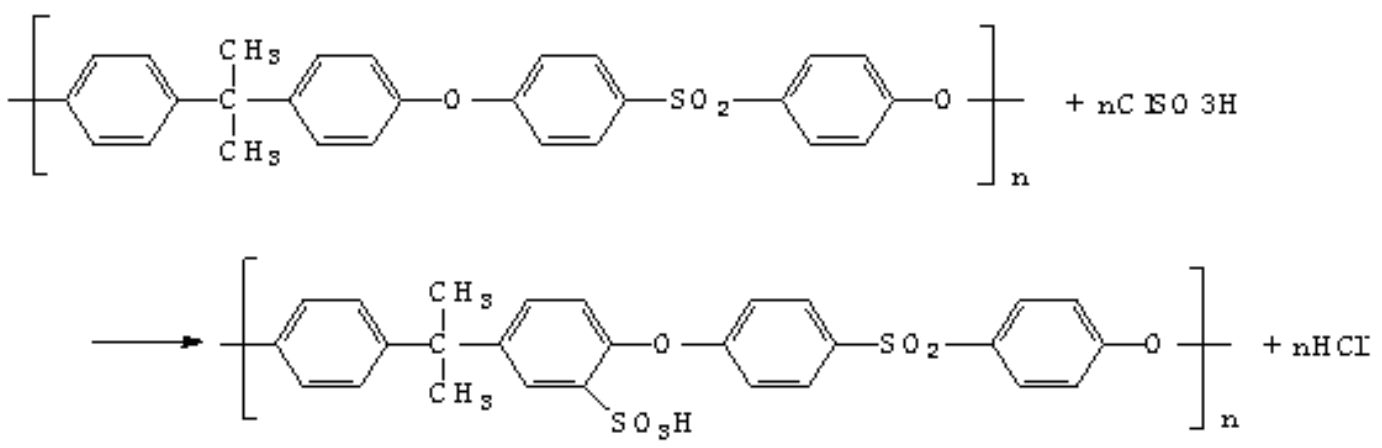

Scheme 1. The preparation of SPSU.

Preparation of the composite membrane

PWA supported on silica gel was prepared by using PWA and silica gel. An appropriate amount of PWA was mixed with silica gel in a water solution. Subsequently, it was stirred in an ultrasonic bath for $30 \mathrm{~min}$. Then the suspension was dried at room temperature. The resulting solid material was crushed in an agatemortar to obtain a fine powder and then it was further dried at $50{ }^{\circ} \mathrm{C}$ for $2 \mathrm{~h}$.

The synthesized SPSU with a degree of sulfonation (DS) of $53 \%$ was used for preparing all the composites. An appropriate amount $20 \%$ SPSU solution was mixed with PWA or $\mathrm{PWA} \mathrm{SiO}_{2}$ powders (weight ratio, SPSU: PWA=8:2) in an ultrasonic bath for $30 \mathrm{~min}$. The composite membranes were prepared by solution casting. The resulting films were transparent with a yellowish color and a thickness of about $50 \sim 150 \mu \mathrm{m}$.

\section{Characterization}

The degradation process and the thermal stability of the samples were investigated using thermogravimetry analysis (TG $209 \mathrm{~F} 1$ Iris). The TGA measurements were then carried out under a nitrogen atmosphere using a heating rate of $10^{\circ} \mathrm{C} \cdot \mathrm{min}^{-1}$ from $30{ }^{\circ} \mathrm{C}$ to $700{ }^{\circ} \mathrm{C}$.

SEM imaging was done to evaluate the uniformity of the dispersion of additives in the membrane and the additive particle/agglomerate size. The imaging was done using a S-3000N SEM. Fresh cross-sectional cryogenic fractures of the membranes were vacuum sputtered with a thin layer of Au prior to SEM examination. 
Water uptake experiment was carried out by immersing the dried membranes in deionized water at room temperature for $24 \mathrm{~h}$ in order to understand the amount of water uptake before and after treatment. For measurement, the membranes were taken out, wiped with filter paper, and immediately weighed. The amount of wateruptake, $\mathrm{W}_{\mathrm{H} 2 \mathrm{O}}$, was calculated using following equation:

$\mathrm{W}_{\mathrm{H} 2 \mathrm{O}}(\%)=\frac{W_{\text {wet }}-W_{d r y}}{W_{d r y}} \times 100$

where $W_{\text {wet }}$ is the mass of the membrane in grams after absorption and $W_{\text {dry }}$ is the mass of the dried membrane in grams.

The amount of PWA extracted from the composite membranes in water was determined with UV-Vis recording spectrophotometer. Before immersing in $30 \mathrm{~mL}$ deionized water at $60{ }^{\circ} \mathrm{C}$ for some time, the prepared dry composite films were weighed. The solvent with extracted PWA was put into a quartz cell and then measured at $260 \mathrm{~nm}$, which shows the maximum absorption spectrum. We can get the extracted PWA concentration $(C)$ from the concentration-absorption UV-Vis spectrum graph and the PWA extraction (\%) was determined from:

$$
P W A \text { extraction }(\%)=\frac{\mathrm{C} \times 30 \mathrm{~mL}}{\text { weight of PWA in sample }} \times 100
$$

The resistance to hydrogen peroxide radical was examined in Fenton's reagents (a $3 \% \mathrm{H}_{2} \mathrm{O}_{2}$ aqueous solution containing $2 \mathrm{ppm} \mathrm{FeSO}_{4}$ ) at $80{ }^{\circ} \mathrm{C}$. The anti-oxidative stability was characterized by the expended time that the membrane started to break into pieces and disappear into solution. Each measurement was carried out repeatedly at last five times to ensure good reproducibility.

Mechanical properties test was measured using an Universal Materials Testing Machine at strain rate of $10 \mathrm{~mm} \cdot \mathrm{min}^{-1}$ on $4 \mathrm{~mm}$ wide $\times 15 \mathrm{~mm}$ long samples.

Membranes equilibrated during immersion in water at room temperature were investigated through determining impedances of SPSU membrane samples to evaluate the proton conductivity $(\sigma)$. The impedances were determined by using the self-made equipment by alternating current [21], The proton conductivity was calculated from following equation:

$\sigma=\frac{l}{R \times S}$

where $\sigma$ is proton conductivity $\left(\mathrm{s} \cdot \mathrm{cm}^{-1}\right) ; R$ is the ohmic resistance of membrane sample $(\Omega) ; \quad /$ is the distance between the electrodes $(\mathrm{cm}) ; S$ is the face area of membrane sample $\left(\mathrm{cm}^{2}\right)$.

The methanol permeability of the composite membranes was determined through a glass diffusion cell [22]. The glass cell consisted of two compartments. One compartment $\left(V_{A}\right)$ was filled with a $10 \mathrm{M}$ methanol solution. The other $\left(V_{B}\right)$ was filled with de-ionized water. The membrane was clamped between the two compartments and these kept under stirring during the experiment. A flux of methanol penetrates across the membrane as a result of the concentration difference between the two compartments. Under pseudo steady-state condition, which prevailed during the experiment and for $C_{B}>>C_{A}$, the methanol concentration in the receiving compartment as a function of time is given by following equation: 
$D c_{B}=\frac{A}{V_{B}} \times \frac{D K}{L} c_{A} \times D t$

where $c$ is concentration, $A\left(\mathrm{~cm}^{2}\right)$ and $L(\mathrm{~cm})$ the membrane area and thickness; $D$ and $K$ are the methanol diffusivity and partition coefficient between the membrane and the adjacent solution, respectively. The assumptions are made in this study that $D$ inside the membrane is constant and $K$ does not depend on concentration. The product $D K$ is the membrane permeability $(P)$.

$P=\frac{L}{A} \times \frac{D c_{B}}{c_{A} D t} \times V_{B}$

where $c_{B}$ was measured several times during the experiment and the permeability is calculated from the slope of the straight line. The methanol concentrations with time were measured using a gas chromatograph. The temperature was kept constant in a thermostatic water bath.

\section{References}

[1] Aramata, A.; Toyoshima, I.; Enyo, M. Electrochim Acta,1992, 37, 1317.

[2] Arico, A.S.; Kim, H.; Shukla, A.K.; Ravikumar, M.K.; Antonucci, V.; Giordano, N. Electrochim Acta,1994, 39, 691.

[3] Won, J.; Kang, Y. S.; Macromol. Symp., 2003, 204, 79.

[4] Woo, Y.; Oh, S.Y.; Kang, Y. S.; Jung, B. J. Membr. Sci., 2003, 220, 31.

[5] Lufrano, F.; Squadrito, G.; Patti, A.; Passalacqua, E. J. Appl. Polym. Sci. 2000, $77,1250$.

[6] Lufrano, F.; Baglio, V.; Staiti, P.; Arico, A.S.; Antonucci, V. Desalination,2006, 199, 283.

[7] Lufrano, F.; Gatto, I.; Staiti, P.; Antonucci, V.; Passalacqua, E. Solid State Ionics, 2001, 145, 47.

[8] Karlsson, L. E.; Jannasch, P. Electrochim Acta, 2005, 50, 1939.

[9] Guo, X.; Fang, J.; Harada, S.; Watari, T.; Tanaka, K.; Kita, H.; Okamoto, K. Macromoleucles, 2002, 35, 9022.

[10] Miyatake, K.; Asano, N.; Watanabe, M. J. Polym. Sci. Part A: Polym. Chem., 2003, 41, 3901.

[11] Wang, J. T.; Savinell, R. F.; Wainright, J.; Litt, M.; Yu, H. Electrochim Acta, 1996, 41,193.

[12] Samms, S. R.; Wasmus, S.; Savinell, R. F. J. Electrochem. Soc. 1996, 143, 1225.

[13] Staiti, P.; Minutoli, M. J. Power Sources, 2001, 94, 9.

[14] Li, L.; Zhang, J.; Wang, Y. J. Membr. Sci. 2003, 226, 159.

[15] Gil, M.; Ji, X.; Li, X.; Na, H. ; Hampsey, J. E.; Lu, Y. J. Membr. Sci.,2004, 234, 75.

[16] Li, L.; Wang, Y. X. J. Power Sources, 2006, 162, 541.

[17] Staiti, P.; Freni, S.; Hocevar, S. J. Power Sources,1999, 79, 250.

[18] Kim, Y. S.; Wang, F.; Hickner, M.; Zawodzinski, T. A.; McGrath, J. E. J. Membr. Sci., 2003, 212, 263.

[19] Smitha, B.; Sridhar, S.; Khan, A. A. J. Polym. Sci. Part B: Polym. Phys.,2005, 48, 1538.

[20] Li, W. D.; Xu, H. Zhao, J. X. Proceedings of 2007 International Conference on Advanced Fibers and Polymer Materials, 2007, pp 624-626.

[21] Li, L.; Xu, L; Wang, Y. Materials Letter, 2003, 57, 1406. 
[22] Park, H. B.; Soo, H.; Lee, Y. M.; Rhim, J. W. J. Membr. Sci.,2005, 247, 103.

[23] Huang, J. C.; Zhu, Z. K.; Yin, J.; Zhang, D. M.; Qian, X. F. J. Appl. Polym. Sci., 2001, 79, 794.

[24] Lee, C. H.; Min, K. A.; Park, H. B.; Hong, Y. T.; Jung, B. O.; Lee, Y. M. J. Membr. Sci., 2007, 303: 258.

[25] Kim, D. S.; Liu, B.; Guiver, M. D. Polymer, 2006, 47, 7871.

[26] Baradie, B.; Dodelet, J. R.; Guay, D. J. Electroanal. Chem., 2000, 489,101.

[27] Kwak, S. H.; Yang, T. H.; Kim, C. S.; Yoon, K. H. Solid State lonics, 2003, 160, 309.

[28] Kim, D. S.; Park, H. B.; Rhim, J. W.; Lee, Y. M. J. Membr. Sci., 2004, 240,37. 